\title{
Descentralização tributária e poder local ${ }^{*}$
}

\author{
Jefferson O. Goulart
}

Resumo

No bojo do processo de democratização institucional, a Constituição Federal de 1988 ensejou um esforço de correção do caráter assimétrico do federalismo brasileiro. Além de atribuir aos municípios o pioneiro estatuto de ente federativo, dotado de autonomia e de personalidade jurídica, caracterizou-se por expressivo aumento das receitas transferidas para as esferas subnacionais de governo. Tal inflexão, porém, revelou-se demasiado precária, datada, ocorrendo um movimento de recentralização no período ulterior, sob a batuta do Executivo federal. Com base em pesquisa comparativa de dois municípios paulistas - Piracicaba e Santa Bárbara d'Oeste -, demonstra-se que este revés não foi suficiente para anular as mudanças processadas nas relações intergovernamentais, cuja característica distintiva é o progressivo aumento de prerrogativas dos municípios, não apenas em sua dimensão tributária, mas também na acepção republicana de assegurar direitos aos cidadãos.

* O presente artigo é uma versão abreviada do paper "Descentralização e Evolução Tributária dos Municípios”, apresentado na Sessão Gestão Local e Estadual II Finanças Públicas, do II Encontro Brasileiro de Estudos Regionais e Urbanos organizado pela ABER (Associação Brasileira de Estudos Regionais e Urbanos), em outubro de 2002, na FEA/USP. O conteúdo é produto da pesquisa que resultou na Tese de Doutorado apresentada ao Programa de Pós-Graduação do Departamento de Ciência Política da FFLCH/USP (Goulart, 2002). 


\section{A Constituição de 1988 e a descentralização}

Comparativamente ao arcabouço precedente impregnado pelo autoritarismo, a Constituição de 1988 representou expressivos avanços no terreno da democratização institucional, particularmente ao reconhecer como princípio fundamental o Estado democrático de direito, $e$, na esfera dos direitos sociais $e$ individuais, ao afirmar garantias $e$ prerrogativas universais. Fundamentalmente por essas razões, recebeu o predicado de Constituição cidadã. Por outro lado, instituiu normas excessivamente detalhistas - caso emblemático do Art. 192, que, ao tratar do Sistema Financeiro Nacional, fixou as taxas de juros reais.

O produto final deste arranjo constitucional sintetiza a sucessão de pactos políticos tópicos verificados ao longo de seu transcurso, tanto em razão da sintomática inexistência de uma maioria de fato hegemônica, quanto pelo enfraquecimento do governo Sarney. Resumidamente, é oportuno recuperar alguns desses sintomas, tais como o fracionamento do PMDB, principal partido de sustentação ao governo, a baixa capacidade de coesionamento do Executivo e de seus líderes no Congresso, além da recorrente fragilidade institucional do sistema partidário. A propósito, o surgimento do Centrão evidenciou a confusão estabelecida, afinal, além de reagir ao ativismo da esquerda, tentava-se instituir uma nova referência política multipartidária capaz de conduzir o processo constitucional. Tal descoordenação política do bloco majoritário também se traduziria no descontrole das bancadas parlamentares, resultando num jogo menos cooperativo e mais competitivo nas definições federativas: prevaleceria um sentimento generalizado de revanche contra o centralismo prevalecente na história republicana, de sorte que, ante a oportunidade de reverter aquela tradição perversa, todos os esforços seriam dirigidos à reforma constitucional, superando-se os alinhamentos estritamente doutrinários, isto é:

Contrariando as expectativas de muitos analistas, os debates na Constituinte no tocante às finanças públicas não foram marcados pelo confronto entre posições progressistas e conservadoras, entre esquerda e direita. Polarizou o debate, sobrepondo-se à questão ideológica, a questão regional e mesmo local - o que levou ferrenhos adversários político-ideológicos a se unirem em defesa de seu estado e região. Assim, foi central a preocupação com a descentralização de recursos da União para os estados e 
municípios e com o fortalecimento de sua autonomia. As questões, por outro lado, que implicavam posições doutrinárias $e$ ideológicas, mereceram uma atenção secundária, sendo tratadas no nível de "princípios" e transferidas para a legislação as decisões para a sua materialização. ${ }^{1}$

Um primeiro desdobramento dessa inclinação desconcentradora seria inscrito no Título I, Dos Princípios Fundamentais, em seu Artigo $1^{\circ}$, e depois confirmado no Título III, Da Organização do Estado, Artigo $18^{\circ}$, ao elevar o município à condição de ente constitutivo do Estado; além de unidade administrativa, o preceito pautar-se-ia pela originalidade ao conceder o estatuto de personalidade jurídica aos municípios, com seu conseqüente fortalecimento e afirmação de sua autonomia.

Embora os resultados finais do processo constituinte tenham revelado a prevalência de um comportamento mais centrista, é digno de registro que o maior número de parlamentares identificados com os espectro de direita e centro-direita estivessem concentrados, respectivamente, nas regiões Norte, Nordeste e Centro-Oeste. Inversamente, esquerda e centro-esquerda tinham mais expressão no Sudeste - não por acaso a região mais penalizada pelas distorções do sistema representativo. Cruzando-se a representação partidária regional com as respectivas localizações no contínuo direita-esquerda, os dados do Congresso Constituinte são bastante ilustrativos. No campo da esquerda, enquanto a bancada do PDT de 26 parlamentares é predominantemente gaúcha e fluminense, a representação constituinte petista não registra nenhum parlamentar eleito nas regiões Norte, Nordeste e Centro-Oeste. À direita, porém, o tendência é inversa: mais da metade da bancada do PFL, 68 de 132 parlamentares, tinha origem no Nordeste, e a soma desta fração com o Norte e o Centro-Oeste totalizava 94 constituintes, ou seja, 71,2\% dos pefelistas. Ao centro, o PMDB expressava menor desequilíbrio regional e mantinha as feições multi-ideológicas internas que se traduziriam na incorporação de seus membros a blocos antagônicos e em múltiplos alinhamentos:

[David] Fleischer, em seu estudo sobre a genealogia partidária, aponta que, da bancada do PMDB na Constituinte, 40 representantes eram oriundos do PDS (10 deles aderiram em $1982 e$ 30 em 1986), e 42 da antiga ARENA. Dos egressos de última

1 Oliveira, 1995: 86. 
hora, ainda segundo Fleischer, $70 \%$ estavam concentrados na região Nordeste, enquanto aqueles originários do PMDB histórico eram preponderantemente da região Sudeste. A realidade revelada por esses números levou [Maria do Carmo] Campello de Souza a afirmar que o maior bancada da Constituinte não foi formada pelo PMDB, mas pela ARENA de 1979: "nada menos que 217 dos 559 constituintes atuais tiveram passagem por esta legenda que apoiou o autoritarismo antes de 1988". ${ }^{2}$

Além da atuação parlamentar fortemente propensa à descentralização, há que se considerar a ação dos governadores estaduais, cujo papel na transição era cada vez mais influente. Em um cenário de fragilidade do Executivo, de incertezas sobre os rumos da democratização, clarificados pela ausência um projeto catalisador e pela fragmentação do sistema partidário, a atuação dos governadores seria preponderante. A ação conjunta desses atores nas redefinições do arcabouço federativo pautar-se-ia pelo que Abrucio (1998) qualificou como "poder de veto", isto é, pela rejeição a mudanças que implicassem saldo negativo na partilha de poder e de recursos. Não é fortuito, portanto, o epíteto de barões cunhado por este autor para identificar o desempenho político dos governadores:

Se no plano nacional os governadores aumentaram seu poder de veto com a redemocratização, na esfera estadual eles se tornaram os grandes comandantes do processo político, com um poder incontrastável ante os outros Poderes e os outros agentes políticos. Foi com base em seu poder nos estados que os governadores conseguiram atuar de forma decisiva no plano nacional, exercendo em determinados assuntos forte influência sobre os deputados no Congresso Nacional. ${ }^{3}$

A combinação da força política dos governadores e de sua ascendência sobre os parlamentares com a pressão exercida pelos prefeitos, sob o ímpeto descentralizador dos constituintes, resultaria em um poderoso movimento que aspirava sangrar a União, drenando parcelas de suas receitas para estados e municípios. O alvo da disputa residia nas transferências. Assim, os lobbies correspondentes dirigiriam seus esforços e suas atenções à Comissão de Tributos, Orçamento e Finan-

\footnotetext{
Leme, 1992: 95.
}

Abrucio, 1998: 108. 
ças e à Sub-Comissão de Tributos, Participação e Distribuição de Receitas, em torno das quais se processaram pactos decisivos e onde foram produzidas as resoluções mais relevantes. Como as escolhas políticas expressam interesses objetivos e racionais dos atores que as protagonizam, as deliberações registradas nada mais significam que a tradução concreta das intenções dos constituintes:

Com efeito, analisando a origem dos componentes da Comissão de Tributos, Orçamento e Finanças, constata-se que 4 deles eram ex-governadores, 2 ex-vice-governadores, 9 ex-prefeitos e 1 ex-vice, além de 11 parlamentares com atividades anteriores em Executivos estaduais e municipais, como secretários de governo. Evidentemente, essa composição tornava a Comissão mais favorável ao fortalecimento financeiro dos estados e municípios, pois, como bem observa [José Roberto] Afonso, eles "estavam ali pensando cada um em seu estado, em sua prefeitura, e pouca gente pensando no país". ${ }^{4}$

Esse jogo de inspiração hobbesiana é facilmente perceptível na divisão do bolo tributário pré e pós-Constituinte. ${ }^{5} \mathrm{O}$ estabelecimento do conflito distributivo está longe se ser casual: a recorrência de problemas centrais como o processo inflacionário e o desajuste fiscal, somados às pressões sociais por mais e melhores serviços públicos e o imperativo de os governantes estaduais e municipais serem responsivos em um cenário já marcado por eleições diretas, tudo concorria para que a disputa por recursos de poder se tornasse efetivamente fratricida. Ausente um sentimento de todo, triunfaria a primazia das partes, ou seja, uma lógica predatória e particularista.

De resto, a União ficaria impedida de conceder incentivos e/ou isenções sobre tributos das alçadas estadual e municipal. Em seu conjunto, poucas seriam as novidades quantitativas do novo sistema. Do ponto de vista da participação das unidades federativas na repartição das receitas, a fraqueza do governo federal e a mobilização dos interesses municipalistas e estadualistas determinariam um resultado marcado pela derrota da União: um jogo de soma zero em que, para os primeiros ganharem, esta última precisaria necessariamente perder. Assim, os estados teriam sob sua batuta três impostos (ICMS, IPVA e

\section{Leme, 1992: 149.}

5 Sobre a distribuição do bolo tributário, ver Tabelas em Oliveira, 1995: 121-2. 
Transmissão Causa Mortis e Doação), enquanto os municípios exerceriam sua competência em outros 4 tributos (IPVA, ISSQN, IVVC e Inter Vivos), mas ambos elevariam suas respectivas participações especialmente através das transferências. A mudança mais expressiva, com efeito, foi a elevação das transferências para as unidades subnacionais, notadamente das fatias dos Fundos de Participação (FPE e FPM).

Muito embora os municípios tenham logrado êxito nos intentos de reforçar sua autonomia governativa e de absorver mais receitas, estes ainda constituem uma esfera demasiado dependente de transferências dos níveis superiores, particularmente dos governos estaduais, que detêm a competência sobre a arrecadação e distribuição do ICMS. Ademais, são conhecidos os costumes políticos brasileiros caracterizados pelo "beija-mão" de prefeitos junto aos governos estaduais, os quais, para deferirem pleitos, não hesitam em exigir alinhamento político (ou mesmo partidário) em contrapartida. Tal constatação apenas realça o poder político dos governadores, que, além de interferir decisivamente nos rumos nacionais, vêem reforçado seu controle sobre a política lo$\mathrm{cal} /$ regional. Favorecidos por este amplo poder sobre a política estadual, por uma dinâmica igualmente preponderante nas relações com as Assembléia Legislativas e ainda pela forte ascendência nos rumos da transição, os governadores tornaram-se peças chaves na redemocratização e, por conseguinte, nos trabalhos constituintes. Ademais, o êxito dos estados caracterizado pelo calote das dívidas será dilatado "pela manutenção de relações predatórias com o governo federal, tal qual bem exemplifica o caso dos bancos estaduais". ${ }^{6}$

Nessa dialética do "salve-se quem puder", típica de uma guerra de todos contra todos, foram favorecidos os que se revelaram capazes de pactuar solução compatível com seus particularismos. Como é sabido, o conceito de guerra implica a destruição do inimigo e talvez constitua certo exagero afirmar que governadores, prefeitos e constituintes desejassem aniquilar a União, mas a Carta produzida conteria um enorme desequilíbrio. Bastante municipalista e especialmente estadualista, a nova Constituição revelaria o peso e a capacidade política dos atores em cena, de tal sorte que permaneceria o desafio de uma interdependência responsável (Abrucio, 1998).

6 Abrucio, 1998: 105. Ainda sobre esta questão, consultar Sola, 1995. 
O novo marco constitucional e a evolução tributária dos municípios: Piracicaba (1989-1992) e Santa Bárbara d'Oeste (1997-2000)

No sentido de representar uma difusão de prerrogativas mais equilibrada entre os níveis de governo, a descentralização é inseparável de sua espinha dorsal: o federalismo fiscal-tributário. Além de um comportamento universalmente responsável no que concerne ao equilíbrio entre receitas e despesas, supõe-se uma justa partilha de recursos tributários, ou seja, para além de enunciado constitucional, o "conceito de autonomia deve traduzir-se na descentralização do poder, no sentido de que as esferas locais possam definir suas prioridades, determinar e gerir os recursos necessários para dar conta delas, de acordo com suas necessidades, especificidades e possibilidades". ${ }^{7}$

Abstraindo seu caráter efêmero e a dinâmica fratricida que levou à sua consagração, Constituição de 1988 engendrou o fortalecimento da autonomia municipal ao elevar suas receitas, notadamente as transferências. O problema fiscal do Estado esteve longe de ser resolvido, como de resto permaneceu instável e frágil a interdependência entre todos os níveis do sistema governativo. O movimento de recentralização verificado na segunda metade da década de 1990 apenas confirma a precariedade do pacto selado em 1988. Não obstante, ocorreu um importante incremento para as finanças municipais: além do aumento da participação no ICMS - de $20 \%$ para $25 \%$ - e no FPM - de $17 \%$ para 20,5\% em 1989 até atingir o patamar de 22,5\% a partir de 1993 -, os municípios passaram a abocanhar 50\% do IPVA e a contar com dois novos tributos, o Inter Vivos e o IVVC. O impacto dessas mudanças seria altamente vantajoso para os governos municipais, que passaram a dispor de novos instrumentos para executar obras e serviços e assim aumentar o estoque de governabilidade. De maneira geral, os municípios também imprimiram um importante e surpreendente movimento de alargamento de suas receitas próprias:

Desde a promulgação da Constituição de 1988 até 1998, o volume de recursos próprios dos municípios elevou-se em cerca de $\mathrm{R} \$ 9,7$ bilhões, um acréscimo de aproximadamente 197\%. Seu crescimento médio anual foi duas vezes mais rápido que o

7 Mafezzoli, 2001: 186. 
dos tributos estaduais e cerca de três vezes o dos federais (...) Isso demonstra que, pelo menos em termos agregados, o crescimento da receita dos municípios após a Constituição de 1988, ao contrário do que normalmente é divulgado, não se deve somente ao aumento das transferências federais e estaduais. Nas grandes cidades, os resultados tendem a ser explicados pela modernização fazendária e, após a estabilização, pela melhoria dos sistemas de avaliação doas propriedades imobiliárias e pelo crescimento dos serviços à frente da indústria e o comércio... ${ }^{8}$

Mesmo as transferências permanecendo como principal fonte de recursos para a esfera municipal e a despeito da relativa menor capacidade de geração de receita dos tributos locais, pode-se verificar uma expansão significativa da arrecadação auferida sobretudo com o IPTU e o ISS. No cômputo geral, o crescimento da arrecadação tributária municipal é expressivo dos dez anos que se seguem à Constituição de 1988 (Afonso \& Araujo, 2000). Superada a euforia do triunfo descentralizador, contudo, a União tomaria diversas iniciativas visando à sua recapacitação financeira, haja vista a sintomática redução de transferências não-constitucionais. Outro fenômeno também concorreria para minimizar a vitória de estados e municípios no período imediatamente posterior à promulgação da nova Carta, qual seja, a recorrência de elevadíssimos índices inflacionários. Embora as unidades subnacionais se comportassem como sócios menores da inflação ao assegurarem algum aporte de recursos relativamente seguro através de aplicações financeiras, eram também penalizadas pelos prazos de retenção e distribuição de créditos praticados pelo Tesouro Nacional. A tendência geral na difusão dos Fundos de Participação é assim demonstrada em um caso particular:

A inflação $e$ as oscilações na arrecadação do IR $e$ do IPI interferiram no volume real das transferências do FPM para Piracicaba. Mas, mesmo assim, o município recebeu mais receita do Fundo [de Participação dos Municípios] em todos os anos após a reforma da Carta do que no ano anterior a ela (1988). Com isso, chegou em 1993, primeiro ano da aplicação do rateio de $22,5 \%$, com um incremento significativo de 34 pontos percentuais. ${ }^{9}$

\footnotetext{
8 Afonso \& Araujo, 2000: 38.
}

9 Souza \& Pires, 2001: 177. 
Iniciada em 1989 e concluída em 1992, a gestão de José Machado (PT) não foi beneficiária da elevação do FPM para o percentual de $22,5 \%$ no ano seguinte (1993), mas a evolução dessa receita revela crescimento desde 1989, portanto logo após a entrada em vigor do novo arranjo tributário. Embora maior, a transferência do FPM estava subordinada à arrecadação da União, razão pela qual é mister considerar a variável macroeconômica, isto é, naquele momento o país atravessava um período instável marcado por ciclos recessivos. Nessas condições, ocorriam importantes variações na arrecadação, tornando instáveis na mesma proporção as transferências, em particular o bolo do FPM..$^{10}$ Ainda sobre o FPM - embora represente, ao lado do FPE, seguramente a maior fatia das transferências constitucionais da União, da ordem de $81 \%$-, é oportuno registrar que se trata de repasse de menor vulto para cidades de porte médio e grande, sendo decisivo para municípios menores, de regiões menos desenvolvidas, cuja arrecadação própria é ínfima e que não contam com atividade econômica local capaz de gerar outras fontes de receita, particularmente através dos repasses do ICMS e de Impostos e Taxas municipais. Uma demonstração inequívoca da importância relativamente inferior do FPM na arrecadação da Prefeitura de Piracicaba pode ser identificada na confrontação com o ICMS, isto é: "no melhor ano, 1990, teve uma participação de $10 \%$ na composição da receita total, e uma média de $8 \%$ no período estudado, enquanto a participação do ICMS foi de $52 \%$ e $42 \%$, respectivamente" ${ }^{11}$

Para Piracicaba e cidades de porte similar, o naco mais polpudo das transferências seria aquele representado pelo ICMS. Não por acaso, o movimento municipalista logrou êxito no processo constitucional ao alargar em $25 \%$ a fatia a ser distribuída aos municípios. Não obstante, mercê também da recorrente crise econômica, o ICMS paulista teve performance modesta nos primeiros anos da década de 1990, determinando recuo nas transferências para os municípios. Outra variável local concorreria, ainda, para ofuscar a arrecadação do ICMS de Pi-

10 Não se deve ignorar que outra importante razão para a diminuição do percentual recebido do FPM foi a proliferação de municípios, após o processo constitucional. À medida que eram criados novas unidades reduzia-se a participação das demais, revelando a dimensão horizontal dos conflitos da Federação que adiciona outra dificuldade para uma coordenação federativa mais responsável (Cf. Affonso, 2000).

11 Souza \& Pires, 2001: 176. 
racicaba no mesmo período, qual seja, a instabilidade de seu correspondente Índice de Participação (Souza \& Pires, 2001). Provavelmente, para além das determinações de caráter macroeconômico ou mesmo do desempenho das finanças paulistas, isto seria decorrência das dificuldades enfrentadas pelo pólo metal-mecânico associado à agroindústria canavieira. Como é sabido, a indústria local de bens de capital viveu um boom na década de 1970 com o apogeu do Proálcool, porém a partir da segunda metade dos anos de 1980 a crise deste programa faria sentir seus efeitos na economia piracicabana.

A despeito dessas dificuldades, o ICMS representava individualmente a principal fonte de receitas do município e teve uma sensível melhora a partir de 1989. Tal como ocorreu com outras receitas transferidas, após elevação em 1989 e 1990, as razões mais plausíveis para a queda verificada a partir de 1991 são o quadro nacional de instabilidade política - datam deste período as primeiras denúncias que culminariam com o impeachment do presidente Collor e o princípio de sua alucinante perda de governabilidade - e o cenário econômico marcado pelas incertezas quanto aos desfechos do modelo de abertura, pela perda de credibilidade do país e pelas fortes pressões externas. Após um breve intervalo de relativa estabilidade em 1990, voltariam à cena o dragão da inflação e o fantasma representado pela crise fiscal do Estado.

Diante das adversidades e mesmo beneficiado com o crescimento das receitas transferidas originárias do arranjo constitucional de 1988, o governo Machado empreendeu um movimento decisivo: operou uma reforma tributária local que ampliou significativamente as receitas próprias. Concluído em 1990, o êxito do novo Código Tributário seria refletido nos números do ano posterior: em 1989, primeiro ano da gestão petista, a arrecadação própria representava $16,4 \%$ das receitas totais; em 1990, o patamar manteve-se baixo, em 14,46\%; nos anos seguintes, contudo, a participação percentual salta para $23,22 \%$, em 1991, e fecha em $28,6 \%$ em 1992. Ao avolumar as receitas próprias, este governo construiu novos instrumentos de governabilidade, ao mesmo tempo em que reduziu a margem de dependência dos níveis superiores - buscando assim afirmar sua autonomia política e financeira. Para enveredar por este percurso, tendo ciência dos custos políticos que o mesmo poderia representar, o cálculo do governo petista pode ser resumido à percepção de que as torneiras dos cofres estadual e federal não mais se abririam, tanto pela reação da União à sua derrota no pacto constitu- 
cional de 1988, quanto pela delicada situação fiscal do Estado ou ainda pelo não-alinhamento político com os níveis superiores de governo. Assim, restaria apenas o alargamento das receitas próprias, sob pena de submeter-se ao colapso e, portanto, à ingovernabilidade.

Quadro 1 - Município de Piracicaba

Demonstrativo (parcial) das Receitas Próprias e das Transferências (1989-1992), com valores expressos em Reais, com base no IGP-Dez/95 ${ }^{12}$

\begin{tabular}{|c|rc|ccc|}
\hline \multirow{2}{*}{ EXERCÍCIO } & \multicolumn{4}{|c|}{ PRINCIPAIS RECEITAS } & \multicolumn{3}{|c|}{ PRINCIPAIS TRANSFERÊNCIAS } \\
& \multicolumn{2}{|c|}{ PRÓPRIAS } & & & \\
& IPTU & ISSQN & ICMS & FPM & IPVA \\
\hline 1989 & 2.230 .531 & 7.294 .461 & 30.121 .798 & 5.008 .476 & 1.438 .078 \\
1990 & 1.465 .188 & 7.896 .218 & 36.563 .607 & 7.064 .852 & 1.194 .359 \\
1991 & 8.667 .744 & 9.244 .026 & 36.334 .069 & 5.672 .326 & 4.322 .002 \\
1992 & 10.583 .170 & 9.653 .381 & 28.749 .848 & 5.400 .246 & 2.985 .672 \\
\hline
\end{tabular}

Em Santa Bárbara d'Oeste, Adilson Basso (PRP) assume a Prefeitura em situação bastante diversa: os efeitos da descentralização tributária pactuada na Constituição de 1988 seriam significativamente mais tênues, o governo federal já engendrava uma vigorosa operação recentralizadora e o cenário econômico já era caracterizado por uma acentuada estabilidade desde 1994, através do ajuste representado pelo Plano Real. Tais diferenças, complexas e nada desprezíveis, exigem distintos critérios analíticos.

Começando pelo controle da inflação, tal cenário implica uma readaptação técnica e mesmo cultural dos gestores públicos no planejamento e na execução orçamentária. Se, antes, os ganhos com aplicações cobriam rombos e tranqüilizavam os governantes mediante uma garantia mínima de correção da moeda - além da possibilidade de permanentes renegociações com credores -, em um quadro estável o orçamento passa a ter papel verdadeiramente real como instrumento de planejamento. Prescinde-se, pois, da aposta no futuro incerto, uma vez que as regras do jogo são mais previsíveis. Exemplo importante dessa modificação reflete-se na arrecadação com operações de crédito da Prefeitura de Santa Bárbara d'Oeste: de R \$ 6.093.487 captados em

12 Fonte: Banco Federativo/Banco Nacional de Desenvolvimento Econômico e Social. Julho, 23, 2001. <http://federativo.bndes.gov.br>; Receita Disponível Ampliada = Receita Tributária Disponível +/- Transferências Voluntárias concedidas pela União. 
1987, esta fonte declina para $\mathrm{R} \$ 1.014 .786$ em $1997 .{ }^{13}$ A variação negativa só pode ser explicada pelo fato de que haviam mudado sensivelmente os padrões econômico-financeiros a partir do controle inflacionário. Um cenário de estabilidade - no qual não se tem o recurso ao floating antes corriqueiro - requer uma conduta menos especulativa, ainda mais responsável no trato das finanças públicas. Tal comportamento é imperativo ante à impossibilidade de os municípios - como de resto qualquer unidade do sistema governativo - contarem com recursos adicionais próprios da ciranda financeira. Pois é em um contexto desse tipo, de transição de uma cultura inflacionária para outra de estabilidade, que o governo de Adilson Basso se inicia, tendo que enfrentar também uma situação fiscal bastante adversa em razão do passivo acumulado pelo município.

Paralelamente ao controle da inflação ocorrem dois movimentos determinantes para a agudização das finanças públicas neste período: a retração econômica e a elevação da dívida pública. A primeira incide negativamente porque o desaquecimento da economia provoca menor captação de tributos, e a segunda é fomentada em razão da sistemática alta dos juros, constituindo assim um círculo vicioso no qual altas parcelas do preço a ser pago pela estabilidade consistem em surtos recessivos e na explosão da dívida. Dito de outra forma:

A estabilização da moeda ao ancorar-se em uma conjugação perversa de câmbio sobrevalorizado e elevadas taxas internas de juros - para tentar contrarrestar os efeitos deletérios sobre o balanço de pagamentos - tende, em um segundo momento, a provocar uma forte retração econômica e no emprego. Este "efeito colateral" - associado à expansão das dívidas públicas explicitou a incongruência atual das antigas bases fiscais e "parafiscais" da pactuação federativa. No bojo deste processo evidencia-se o caráter inconcluso e conflitivo da descentralização e do revigoramento do federalismo brasileiro no período recente. ${ }^{14}$

Em segundo lugar, a gestão de Basso coincide com o primeiro mandato presidencial de FHC, cuja tônica - além de operar a reforma do Estado e a abertura econômica do país - pautou-se por engendrar

13 Sobre os indicadores financeiros, consultar o site da Fundação Seade: < http:// www.seade.gov.br>.

14 Affonso, 2000: 139. 
um novo enquadramento nas relações intergovernamentais presidido pela obstinada tentativa de superação do desequilíbrio fiscal. Nesses termos, o arrocho sobre os governos estaduais, sobretudo através do controle dos bancos públicos, se fez acompanhar de sucessivos contingenciamentos orçamentários e de outras medidas de ajuste - como a implementação da Lei Complementar n. ${ }^{\circ}$ 87/96 (a "Lei Kandir") e a prorrogação do então Fundo Social de Emergência (depois Fundo de Estabilização Fiscal) -, que, além de atingirem duramente os estados, no conjunto também afetaram negativamente a arrecadação dos municípios. Em resumo, na tradição pendular do jogo federativo brasileiro, este período é marcado por um movimento de recentralização, isto é, "a absoluta prioridade dada pelo governo à busca de um alívio às questões fiscais deu o tom à busca, ainda em andamento, de um redesenho das relações intergovernamentais". ${ }^{15}$

Em terceiro lugar, e relacionado ao aspecto anterior, a despeito de o cenário de estabilidade da moeda também se refletir em um relativo equilíbrio da arrecadação pública, a segunda metade da década de 1990 já não expressaria a tendência de seus primeiros anos no que concerne ao aumento das transferências para as unidades federativas subnacionais, mesmo tendo ocorrido um expressivo aumento da carga tributária e da arrecadação da União. Acrescente-se a este aspecto a tendência nada banal de multiplicarem-se as demandas da sociedade por serviços públicos, fruto da crise socioeconômica. Isto ocorre tanto porque o governo federal absolutiza a perseguição do equilîbrio fiscal - o que não corresponde necessariamente a lograr êxito nesta empreitada, sobretudo em razão do paradoxo enfatizado por Affonso (2000) -, quanto porque busca suporte para seus próprios empreendimentos lançando mão de diversos instrumentos de concentração e de retenção de recursos, incluindo neste comportamento o rígido controle sobre as transferências não-constitucionais, a elevação de alíquotas de tributos e mesmo a criação de outros não sujeitos ao compartilhamento com estados e municípios. Para verificar tais efeitos na partilha tributária, vale destacar que "a participação federal na receita disponível passa de 61,1\% em 1989 para $56,4 \%$ em 1996 . A dos estados cresce de $25 \%$ a $27 \%$ enquanto a parcela dos municípios sobe de $13,9 \%$ a $16,7 \%$ no mesmo período". ${ }^{16}$

15 Kugelmas \& Sola 2000: 74.

16 Varsano, 1998 et al. apud Kugelmas \& Sola, 2000: 69. 
Os dados do final da década de 1990 demonstram pequenas variações naquele período e confirmam que havia sido estancada a tendência às transferências, ocorrendo efetivamente uma recuperação financeira do governo federal. Se é verdadeiro que os patamares não regridem àqueles do início dos anos 90 , com a elevação global da arrecadação da União e a limitação das receitas transferidas, é indiscutível a ocorrência de uma inflexão concentradora de recursos. Na melhor tradição do federalismo predatório brasileiro, o jogo de soma zero representaria perdas para estados e municípios. Em termos comparativos com o período datado pelo regime militar, o termômetro da descentralização na era democrática demonstra uma melhoria da participação das esferas subnacionais, mas a confrontação com países desenvolvidos ainda coloca o Brasil em um patamar de alta concentração de recursos, como pode ser confirmado no contraponto com o exemplo da Suécia, país no qual "o governo central se contenta com $28 \%$ dos recursos públicos, enquanto as estruturas locais de gestão, que permitem participação muito mais direta do cidadão, controlam cerca de $72 \%$ ". ${ }^{17}$ Já na Espanha, o gasto público exercido pelos governos locais e regionais passa de $11 \%$ para $26 \%$ na década de 1980 (Cf. Mendoza, 1996).

Quadro 2 - Termômetro da Descentralização

Participação Percentual das Unidades Federativas (1997-2000) ${ }^{18}$

\begin{tabular}{|c|c|c|c|}
\hline \multirow{2}{*}{ FLUXOS ANUAIS } & \multicolumn{3}{|c|}{ RECEITA DISPONÍVEL AMPLIADA } \\
\hline & União & Estados & Municípios \\
\hline 1997 & 59.52 & 26.91 & 13.56 \\
\hline 1998 & 58.74 & 26.19 & 15.08 \\
\hline 1999 & 59.73 & 25.01 & 15.26 \\
\hline 2000 & 58.84 & 25.80 & 15.36 \\
\hline
\end{tabular}

Regressando ao caso específico do FPM no Brasil, mesmo havendo razoável elevação de seu bolo global no período que coincide com a gestão de Adilson Basso, esta variação positiva não é suficiente para alterar o panorama de municípios como Santa Bárbara d'Oeste

17 Dowbor, 1994: 8.

18 Fonte: Banco Federativo/Banco Nacional de Desenvolvimento Econômico e Social. Julho, 23, 2001. <http://federativo.bndes.gov.br>; Receita Disponível Ampliada $=$ Receita Tributária Disponível $+/$ - Transferências Voluntárias concedidas pela União. 
face à manutenção dos critérios de rateio que beneficiam municípios pequenos e pelas razões antes enunciadas: trata-se de transferência relativamente de menor relevância para cidades de portes médio e grande, a qual responde, neste caso, por cerca de $15 \%$ de sua arrecadação; o surgimento de centenas de municípios contribuiu para diminuir a participação individual dos demais preexistentes; a transferência de maior impacto é efetivamente o ICMS. O significativo aumento das transferências do FPM, porém, não acompanhou na mesma proporção o extraordinário crescimento da arrecadação da União. Enquanto o repasse do FPM tem uma variação positiva da ordem de $40 \%$ de 1996 a 2000, a execução orçamentária do Executivo federal aumenta cerca de $52 \%$ no mesmo período. ${ }^{19}$

Quadro 3 - Fundo de Participação dos Municípios - FPM

Evolução das Transferências em Reais (1996-2000) ${ }^{20}$

\begin{tabular}{|c|c|c|}
\hline ANO & FPM TOTAL & VARIAÇÃO \\
\hline 1996 & $9.142 .303 .639,11$ & - \\
1997 & $10.333 .725 .577,34$ & $13 \%$ \\
1998 & $10.417 .131 .126,59$ & $8 \%$ \\
1999 & $11.663 .211 .236,34$ & $11 \%$ \\
2000 & $12.816 .400 .875,72$ & $9.8 \%$ \\
\hline
\end{tabular}

As diferenças de tais indicadores confirmam que a era FHC promove uma política de ajuste que, ao enfrentar os dilemas da estabilidade e da crise fiscal do Estado, simultaneamente concentra recursos de poder em sua própria alçada decisória. ${ }^{21}$ Ao movimentar o pêndulo

19 Para uma verificação das despesas da União, consultar o site do Ministério do Planejamento: <http://www.planejamento.gov.br>. No período 1996/2000, o orçamento efetivamente realizado pelo Poder Executivo federal, em valores correntes, é o seguinte: 1996: $\mathrm{R} \$ 116.190 .654 .488$; 1997: $\mathrm{R} \$ 130.382 .124 .208$; 1998: $\mathrm{R} \$ 140.073 .065 .938 ; 1999: \mathrm{R} \$ 153.618 .367 .850 ; 2000: \mathrm{R} \$$ 177.604.760.404.

20 Fonte: Ministério da Fazenda/Secretaria do Tesouro Nacional. Julho, 23, 2001: $<$ http://www.tesouro.fazenda.gov.br>.

21 A propósito, no governo FHC, o movimento de recentralização verificado na dinâmica federativa é perfeitamente harmônico e compatível com a centralização institucional no âmbito das relações entre Executivo e Legislativo, conformando um padrão que, embora respeitasse as regras do jogo democrático, concentrou recursos decisórios. A respeito, consultar Figueiredo et al., 2000 e Sallum Jr., 2000 . 
federativo em sua direção, o governo federal acentua a assimetria de prerrogativas relativamente a estados e municípios, ocasião em que, diversamente do pacto originário da Constituição de 1988, verifica-se resultado negativo para estes.

Voltando, então, ao principal foco de atenção e de dependência das receitas transferidas dos municípios médios e grandes, o ICMS, a Prefeitura de Santa Bárbara d'Oeste sofre com seus efeitos negativos. Esta transferência não acompanha o volume das demandas locais em razão dos obstáculos experimentados, como as crises dos setores têxtil e agroindustrial - principais pólos dinâmicos da economia local. Tal dificuldade iria se refletir no Índice de Participação do município.

Deve-se problematizar a questão nos seguintes termos: o ICMS registrou declínio ou não aumentou o suficiente? Na verdade, ambos os movimentos aconteceram: tanto o Índice de Participação declina, com redução do repasse em 1998, como, em um cenário de crise socioeconômica, seu crescimento nominal é inferior ao enorme volume de demandas por serviços públicos. De 1996 até 1999, o ICMS se manteve estável, verificando-se uma variação positiva mais expressiva somente em 2000 , da ordem de $22,5 \%$, mudança esta que pode ter explicação na recuperação do pólo têxtil a partir do ano anterior, momento em que a mudança cambial promovida pelo governo federal contribuiu decisivamente para que este segmento fosse reanimado $e$ aumentasse sua competitividade. Mesmo observadas as adversidades, o ICMS permaneceu representando a principal fonte de receita do município: no primeiro ano do mandato de Basso, 1997, esta transferência representa $37,6 \%$ da arrecadação, culminando com a marca de praticamente $30 \%$ em 2000 . Na média da gestão, equivale a nada menos que $1 / 3$ do total dos recursos arrecadados. Assim, é natural que as atenções dos governantes se voltem para sua capital fonte de energia financeira.

Os números da evolução das receitas na gestão de Basso revelam, porém, que o problema residia menos nas transferências e mais na receita tributária própria. A rigor, cumpre enfatizar que a dependência de transferências por parte dos municípios não constitui novidade na dinâmica federativa brasileira (Dias, 1995). Concretamente, ao longo de 4 anos, as transferências correntes têm uma variação nominal positiva da ordem de $57 \%$, enquanto a receita tributária cresce apenas $36 \%$. Em 1997, as receitas próprias representam pouco mais de $16 \%$ 
da arrecadação total, regredindo para cerca de $14 \%$ em 2000. O fato de as transferências correntes representarem, na média, aproximadamente $70 \%$ das receitas totais confirma dois aspectos inteiramente imbricados: a baixa capacidade de geração de recursos próprios do município e, por conseqüência, a acentuada dependência dos repasses dos níveis federativos superiores. Nessas condições, falar de autonomia é no mínimo temerário.

A bem da verdade, a noção de baixa capacidade oculta constrangimentos de natureza política. Mesmo admitindo-se como lícita a discutível tese de que a carga tributária nacional seria demasiado alta ${ }^{22}$ - e sobretudo injusta à medida que penaliza os assalariados, onera a produção e possui uma base relativamente estreita, além de seu caráter regressivo -, e que a instabilidade econômica motiva inadimplência e sonegação ou ainda que conspira contra o desenvolvimento, há instrumentos capazes de minorar distorções e promover justiça tributária mesmo no âmbito municipal. Ocorre que a escolha deste percurso implica desgaste pela antipatia inerente a qualquer debate envolvendo adequação de tributos.

Quadro 4 - Município de Santa Bárbara d'Oeste

Evolução (parcial) das Receitas Transferidas (1996-2000) Valores Expressos em Reais ${ }^{23}$

\begin{tabular}{|c|c|c|c|}
\hline ANO & ICMS & FPM & IPVA \\
\hline 1996 & $16.403 .358,76$ & $5.332 .951,55$ & $1.866 .352,39$ \\
1997 & $16.995 .481,43$ & $6.016 .728,40$ & $2.610 .554,93$ \\
1998 & $16.587 .225,16$ & $9.338 .982,10$ & $3.096 .041,28$ \\
1999 & $17.030 .560,94$ & $10.066 .867,88$ & $3.214 .800,35$ \\
2000 & $20.870 .507,25$ & $11.458 .559,98$ & $3.453 .326,77$ \\
\hline
\end{tabular}

22 Conforme Varsano et al. (1998), a carga tributária do país elevou-se para aproximadamente $29 \%$ do Produto Interno Bruto, mantendo-se nesse patamar desde 1994. De resto, a possibilidade de ser reduzida é bastante remota em razão do crescimento das despesas e da demanda reprimida por serviços e investimentos públicos. Comparativamente a países desenvolvidos, a efetiva carga tributária brasileira em relação ao PIB é modesta: na Suécia atinge 54.84\%, na Dinamarca $52.45 \%$, na França 45.59, no Canadá $38.53 \%$ e nos Estados Unidos tem um nível similar: $29.74 \%$.

23 Fonte: Prefeitura do Município de Santa Bárbara d'Oeste/Secretaria de Finanças: Balancetes Analíticos da Receita. 
Embora a Constituição de 1988 não tenha estendido o poder residual, restrito à União, os municípios dispõem de instrumentos próprios para otimizar suas respectivas receitas tributárias. Registre-se que não estão em cogitação estratégias de soma zero como a guerra fiscal ou recursos mais complexos como a progressividade - à época ainda não regulamentada e objeto de intensas disputas jurídicas. As ferramentas mais triviais aqui aventadas consistem na sofisticação da ação fiscalizatória, mediante o aprimoramento da administração fazendária, e na atualização de tributos municipais. Dessa perspectiva, a comparação com a experiência de Piracicaba é inescapável, uma vez que naquela o enfrentamento da escassez de receita mereceu uma atenção política verdadeiramente central, traduzindo-se em substantiva elevação dos recursos próprios. Retomando os números, nos últimos anos de gestão, enquanto Piracicaba (1992) contava com aproximadamente $28 \%$ de receitas próprias, Santa Bárbara d'Oeste (2000) contabilizava pouco mais de $16 \%$ no mesmo quesito.

Para reformar e atualizar o Código Tributário municipal são necessárias condições elementares como vontade política dos governantes, capacidade de persuasão e celebração de pactos que impliquem visualização de como a majoração tributária reverterá em benefícios para a sociedade. Trata-se, pois, de operação altamente complexa, cuja engenharia política exige credibilidade entre os interlocutores e flexibilidade nas negociações, além de pertinácia. Sem o preenchimento de todas essas condições, é improvável que qualquer acordo seja construído, mesmo porque pactuá-lo implica identificar incentivos minimamente vantajosos para todos os atores. No caso em tela, nada disso ocorreu, o que permite compreender a escassez de governabilidade traduzida na insuficiência de recursos orçamentários e na dependência das receitas transferidas.

A autonomia restrita tem elevada dimensão voluntária à medida que, dentre seus ingredientes, também reside a disposição (ou não) de os respectivos gestores edificarem capacidade de governo. Em suma, à guisa de obter instrumentos governativos mais eficazes, para além do recurso às receitas transferidas, seria indispensável promover a recuperação e a elevação das finanças próprias - o que não aconteceu concretamente em Santa Bárbara d'Oeste em razão dos cálculos do governo de que tal opção ou não seria factível ou representaria excessivo desgaste. Foi uma escolha estritamente política, com custos políticos e fi- 
nanceiros correspondentes, o que relativiza a afirmação de que "tende a ser cada vez mais coisa do passado a idéia de que municípios não se interessam por investir na modernização tributária e fiscal, não querem participar de um processo ordenado de transferência de encargos e, acima, de tudo, não procuram contribuir para o ajuste fiscal do país" ${ }^{24}$

Naturalmente, a análise geral do período não perde sua validade como macroexplicação das redefinições do equilíbrio tributário e fiscal do país, mas o caso empiricamente analisado constitui uma exceção relevante à medida que trata-se de um município de porte médio com substantiva capacidade de geração de recursos próprios que não levou a cabo tal intento basicamente pela prevalência de um cálculo receoso por perda de sustentação social e institucional. Nessas condições, a velha tradição populista de evitar medidas impopulares e de responsabilizar terceiros por seus próprios obstáculos ainda está longe de ser superada nos costumes políticos brasileiros.

Quadro 5 - Município de Santa Bárbara d'Oeste Evolução das Receitas Próprias e das Transferências (1997-2000) ${ }^{25}$ Valores expressos em Reais

\begin{tabular}{|l|c|c|c|}
\hline ANO & $\begin{array}{c}\text { RECEITA } \\
\text { TRIBUTÁRIA }\end{array}$ & $\begin{array}{c}\text { TRANSFERÊNCIAS } \\
\text { CORRENTES }\end{array}$ & $\begin{array}{c}\text { TOTAL DAS } \\
\text { RECEITAS }\end{array}$ \\
\hline 1997 & $7.230 .345,73$ & $30.313 .186,07$ & $45.159 .462,21$ \\
1998 & $7.411 .856,28$ & $36.745 .463,53$ & $51.691 .915,15$ \\
1999 & $7.017 .749,29$ & $41.130 .902,82$ & $57.094 .425,63$ \\
2000 & $9.838 .201,10$ & $47.603 .512,88$ & $69.583 .826,07$ \\
\hline
\end{tabular}

Como vem sendo demonstrado, a difusão de recursos esteve longe de oferecer uma solução definitiva para os impasses do sistema federativo nacional, tanto porque há outras importantes variáveis a considerar - todas relacionados ao problema central da governabilidade -, quanto porque, como asseveram Kugelmas e Sola (2000), o problema efetivamente não se resume à díade que opõe ajuste fiscal (perseguido pelo governo federal) à descentralização tributária (reclamada pelas unidades subnacionais). A questão em tela é a estrutura do sistema federativo como um dever ser constituído por múltiplos pólos de poder

24 Afonso \& Araujo, 2000: 53.

25 Fonte: Prefeitura do Município de Santa Bárbara d'Oeste/Secretaria Municipal de Finanças: Balancetes Analíticos da Receita. 
caracterizado por uma dinâmica competitiva que também deveria comportar cooperação, enfim, coordenação federativa e interdependência responsável capazes de precisar direitos - recursos, autonomia etc. $-e$ simultaneamente, deveres - equilíbrio fiscal, responsabilização por determinadas políticas públicas etc. -, de tal forma que os três níveis de poder pudessem ter atribuições igualmente precisas, minimamente integradas e racionalmente eficazes.

Tais reordenamentos não lograriam êxito sem que fossem acompanhados de correções nos sistemas político e eleitoral ou mesmo de redefinições constitucionais das competências das unidades federadas, o que apenas corrobora o argumento de que "mais do que um pacto definitivo, talvez inatingível, deve-se pensar em um processo contínuo de redefinição e aperfeiçoamento". ${ }^{26}$ Ora, se este desafio de reformar o Estado sob a perspectiva de recuperação do caráter republicano das instituições já encontra obstáculos gigantescos que o tornam autêntico esforço de Sísifo, somam-se ainda duas dimensões nevrálgicas e recorrentes, motivadoras de tensões e ainda sem solução, quais sejam, as desigualdades sociais e as clivagens regionais:

A descentralização sem a incorporação de conteúdos sociais condizentes com uma trajetória de longo prazo de inclusão social tende a reproduzir, como estamos assistindo atualmente, outras formas de desigualdade (tanto interpessoais como inter-regionais). A dificuldade de estruturar um novo pacto federativo, sobre uma base social mais ampla, reside, de um lado, na defesa do status quo por parte dos setores sociais privilegiados e, de outro lado, nas extremas disparidades regionais do país. Estes dois fatores dificultam a adoção de políticas gerais e a pactuação regionalizada. A nação encontra-se, assim, no fio da navalha, entre uma trajetória de coordenação federativa e outra, de recentralização. ${ }^{27}$

A Federação, com efeito, está na encruzilhada: precisa oferecer respostas a dilemas que, embora longe de serem inéditos, permanecem desafiando o sistema político, e que a efêmera difusão tributária do final da década de 1980 e dos primeiros anos de 1990 revelou-se incapaz de solucionar.

26 Kugelmas \& Sola, 2000: 79.

27 Affonso, 2000: 149. 
Algumas conclusões são dedutíveis. A primeira delas consiste no imperativo de que os municípios ampliem sua capacidade de gerar receita, seja para diminuir a dependência das unidades superiores e, assim, afirmar sua autonomia, seja para atender as demandas sociais que lhes são dirigidas. Naturalmente, face às gritantes disparidades do país, tal empreendimento é impensável se não for acompanhado de uma intervenção global capaz de desconcentrar o desenvolvimento $e$ de torná-lo sustentado - estratégia esta tipicamente de Estado. No caso de regióes mais desenvolvidas, como a aqui retratada, existem instrumentos disponíveis para otimizar a ação das Prefeituras, cumprindo observar a variável estritamente política do comportamento dos governos. Embora tenha duplicado em 14 anos - passando de 2,7\% em 1982 para 5,4\% em 1996 -, a participação dos municípios na arrecadação nacional ainda é bastante limitada. Seja como for, não haverá um equilíbrio mais simétrico entre os níveis federativos enquanto os municípios permanecerem altamente dependentes e não elevarem suas receitas próprias.

Naturalmente, não se advoga a majoração tributária com simplismo inócuo, afinal um macro (re)arranjo dessa natureza requer amplo debate democrático envolvendo Estado e sociedade civil, além de elevado grau de consenso. Apesar dos complexos empecilhos, trata-se de percurso inadiável para a construção de um desejável cenário de estabilidade, crescimento e justiça. Ademais, é importante assinalar que os tributos de competência dos municípios não têm potencial cumulativo como alguns de prerrogativa da União - casos emblemáticos da Cofins, do PIS e da CPMF -, constatação que, em tese, facilita o desafio de fortalecer a autonomia do Poder Local.

A segunda dedução diz respeito à necessidade de o planejamento e a implementação de políticas públicas serem permeados por controle público. Não só as parcerias e diferentes modalidades de cooperação são indispensáveis, como o ato de partilhar prerrogativas tende a promover eficácia ao tornar mais transparente a gestão pública: coloca-se aqui um elemento crucial que não é outro senão o da democratização do Estado. Novos formatos de participação civil nas definições orçamentárias, nos conteúdos e na execução de políticas públicas alargam o exercício democrático para além do sufrágio, conferindo à cidadania política um caráter mais ativo. Conceitualmente, é importante fazer um duplo registro: tal participação não substitui a democracia 
representativa nem tampouco confunde-se com a responsabilidade precípua do Estado de prover a sociedade de bens e serviços, distinguindo-se, por seu caráter autônomo - no sentido de não se submeter à lógica estatal $e$ aos interesses de quaisquer governos de turno -, e pelo reconhecimento de que a interação engendra potencialmente resultados mais eficazes na gestão pública.

Quadro 6 - Municípios de Piracicaba e de Santa Bárbara d'Oeste (SBO)

Evolução (parcial) de Receitas Transferidas (1987-1997) - Valores expressos em Reais de 199728

\begin{tabular}{|c|c|c|c|c|c|c|c|c|}
\hline \multirow[t]{3}{*}{ ANO } & \multicolumn{8}{|c|}{ FINANÇAS PÚBLICAS MUNICIPAIS } \\
\hline & \multicolumn{2}{|c|}{ ICMS } & \multicolumn{2}{|c|}{ FPM } & \multicolumn{2}{|c|}{ IPVA } & \multicolumn{2}{|c|}{$\begin{array}{c}\text { Transferências } \\
\text { Correntes }\end{array}$} \\
\hline & Piracicaba & $\mathrm{SBO}$ & Piracicaba & $\mathrm{SBO}$ & Piracicaba & $\mathrm{SBO}$ & Piracicaba & SBO \\
\hline 1987 & 31.253 .484 & 8.990 .655 & 6.420 .778 & 3.580 .064 & 887.093 & - & 43.150 .678 & 16.209 .474 \\
\hline 1988 & 26.281 .213 & 8.611 .446 & 5.844 .811 & 3.256 .413 & 642.598 & 122.036 & 39.395 .561 & 14.082 .147 \\
\hline 1989 & 36.476 .299 & 14.143 .324 & 6.009 .439 & 3.579 .463 & 506.032 & 108.414 & 48.155 .504 & 21.657 .201 \\
\hline 1990 & 43.655 .807 & 17.261 .811 & 8.211 .484 & 4.713 .895 & 953.988 & 190.763 & 58.867 .904 & 24.530 .559 \\
\hline 1991 & 41.233 .519 & 15.329 .707 & 6.698 .772 & 4.390 .781 & 3.082 .815 & 620.418 & 56.513 .397 & 23.794 .697 \\
\hline 1992 & 33.244 .875 & 12.708 .450 & 6.685 .439 & $3.571 / 060$ & 1.432 .764 & 250.784 & 45.536 .214 & 18.440 .716 \\
\hline 1993 & 31.271 .095 & 12.116 .644 & 6.900 .776 & 4.784 .873 & 977.974 & 182.856 & 44.006 .736 & 19.425 .397 \\
\hline 1994 & 34.421 .195 & 12.837 .711 & 6.386 .455 & 4.510 .644 & 1.595 .782 & 241.381 & 46.760 .251 & 20.896 .582 \\
\hline 1995 & 49.680 .279 & 17.218 .639 & 7.725 .942 & 5.580 .847 & 7.304.776 & 1.548 .084 & 72.243 .177 & 27.617 .521 \\
\hline 1996 & 46.070 .709 & 17.701 .203 & 6.206 .304 & 5.754 .898 & 8.306 .431 & 2.014 .019 & 68.200 .163 & 28.962 .805 \\
\hline 1997 & 50.076 .900 & 16.995 .481 & 9.687 .224 & 6.016 .728 & 9.629 .228 & 2.610 .555 & 78.317 .761 & 30.313 .186 \\
\hline
\end{tabular}

\section{Descentralização provisória e fortalecimento dos municípios}

Comparativamente ao sistema tributário instituído em 1966 pelo regime autoritário, o resultado constitucional de 1988 consagrou a tendência à descentralização, bastando observar o aumento significativo das transferências e o crescimento da participação das unidades subnacionais na receita disponível. $\mathrm{O}$ aumento de prerrogativas e de suas respectivas participações nas receitas, com efeito, elevou o papel de estados e municípios, promovendo simultaneamente o enfraquecimento da União e conferindo um aspecto original menos assimétrico ao federalismo brasileiro, a despeito das sabidas distorções e disfunções. A

28 Fonte: Fundação Seade. Informações dos Municípios Paulistas. Julho, 19, 2001. $<$ http://www.seade.gov.br/lingcv98/?n1=45>. 
noção de descentralização é válida basicamente por duas razões: primeiro, porque é confrontada com o período precedente - reconhecidamente centralizador; segundo, porque, mesmo não sendo resultado de um desejo unilateral do governo central, só foi possível graças à dinâmica quase exclusivamente competitiva. Em princípio, pareceria mesmo inquestionável que a famosa metáfora que associa o movimento de diástole com descentralização seria suficientemente esclarecedora, afinal a sístole correspondente à centralização estaria definitivamente sepultada com uma nova ordem democrática. Esta, porém, é apenas uma parte das deduções possíveis deste processo, e está longe de encerrar o problema.

Tal simplificação não é suficiente para explicar a transição brasileira. Em primeiro lugar, porque a descentralização financeira e tributária é uma tendência anterior à democratização propriamente institucional (Dias, 1995), sobretudo a partir dos sinais de crise do regime e da aprovação da Emenda Passos Porto; em segundo lugar porque os movimentos de liberalização e de democratização obedeceram a lógicas distintas - o primeiro patrocinado pelo regime e o segundo fomentado pela sociedade civil (Sallum Jr., 1996) - que se traduziram em "uma modificação do padrão de relacionamento entre as esferas, através de uma dinâmica de aperto/afrouxamento de controles políticos e fiscais"; ${ }^{29}$ por último e não menos importante, fruto da precariedade do pacto selado em 1988, porque o período subseqüente, já em uma situação de acentuada estabilização democrática, ocorreria um fenômeno inverso de concentração de recursos pela União.

Sobre este último aspecto, a reconcentração tributária e financeira, vale a pena registrar que, se o colapso do regime militar desnudou uma extraordinária crise de sustentação e de legitimidade, uma nova hegemonia digna deste nome somente seria edificada a partir de 1994, com a eleição de FHC, conquista que lhe permitiu imprimir um forte ritmo reformista. Não por acaso foram implementadas medidas que subverteriam o pacto de 1988, a começar pelo ajuste econômico pautado pela estabilidade e a obcecada busca pelo ajuste fiscal. De resto, não deve ser ignorado o momento de intensas transformações mundiais, marcado pela tendência à internacionalização econômica com conseqüente pressão à abertura de mercados, configurando um cená-

29 Sallum Jr, 1996: 64. 
rio no qual prevaleciam estratégias liberalizantes. Pois é neste cenário que o governo FHC introduz mudanças drásticas que inverteriam o resultado constitucional de 1988, a saber: a) implantação do Fundo Social de Emergência (depois Fundo de Estabilização Fiscal), o qual implicou redução nas transferências; b) entrada em vigor da "Lei Kandir", cuja essência representava a isenção do ICMS para exportações, penalizando os estados; c) renegociação em bloco das dívidas dos estados mediante comportamento rigoroso e pouco flexível; d) intervenção em bancos estaduais, caso emblemático do Banespa já em 1994, como passo primeiro para privatizá-los; e) contingenciamento do Orçamento, de modo a buscar equilíbrio fiscal através da redução dos gastos e obtenção de superávits primários; f) reformas constitucionais estruturais, em especial a da Previdência, com o objetivo de interromper seus déficits recorrentes.

Tais medidas visavam salvaguardar o Plano Real, mantendo a inflação sob controle - pedra de toque da vitória política do governo -, e promover o ajuste fiscal do Estado. Não cabe aqui emitir juízo de valor sobre a correção das políticas do governo FHC - inclusive sobre a política cambial $e$ as relações de interdependência que determinariam o choque de janeiro de 1999 ou ainda sobre os ciclos recessivos característicos de uma performance econômica tipicamente stop and go -, mas apenas enfatizar que representaram uma nova concentração de recursos pela União, anulando a precedente vitória de estados e municípios. Em grande medida, pode-se concluir que tais medidas identificaram as precariedades do pacto constitucional de 1988. Se não foram enfrentadas nos governos de Fernando Collor e de Itamar Franco é porque lhes faltaram recursos: ao primeiro estoque de governabilidade $e$, ao segundo, tempo, ou ainda vontade política. Seja qual for o prisma interpretativo, parece bastante evidente que a democratização não é necessária e obrigatoriamente parteira e guardiã da descentralização.

O fato é que o marco constitucional de 1988 caracterizou-se pela descentralização de receitas para estados e municípios sem correspondente atribuição de responsabilidades, com decorrente esvaziamento da União. Este resultado traduziu o comportamento predatório dos atores em disputa, cuja dinâmica política poderia ser resumida à agonia do governo Sarney e à ascensão dos governadores. A fragilidade deste arranjo despertaria respostas perversas expressas na elevação de alíquotas de tributos exclusivos da União, na redução de transferências não-cons- 
titucionais e na limitação de créditos aos governos subnacionais, especialmente aos bancos estaduais, donde se conclui que "a descentralização de recursos promovida pela reforma de 1988 e a reação que a ela se seguiu revelaram-se, assim, incapazes de dar uma solução satisfatória também aos problemas financeiros dos governos".$^{30}$ Não só foram incapazes de equacionar este problema, como o agudizaram em razão da permanência do desajuste fiscal e do modesto desempenho da economia nacional. É razoável supor, portanto, que faltou racionalidade àquela formatação, afinal não se resolve o problema do desequilíbrio federativo simplesmente invertendo lugares. Ao fim e ao cabo, o pacto constitucional de 1988 demonstrou-se historicamente provisório, datado, demasiado precário face às distorções do equilíbrio federativo erigido. Os acontecimentos seguintes apenas confirmam essa percepção sobre a ausência de uma interdependência responsável, cuja expressão mais latente, para além dos ziguezagues centrípetos e centrífugos nos quais têm prevalecido os primeiros, é a não realização de uma reforma tributária que permita ao Estado enfrentar os desafios do desenvolvimento e de um equilíbrio cooperativo entre as diferentes unidades federativas. A guerra fiscal entre estados e a emissão de precatórios pelos municípios são apenas a ponta do iceberg deste jogo de resultado negativo.

Pode-se argumentar que o governo FHC, à luz de suas necessidades conjunturais, já teria promovido uma reforma tributária silenciosa ao elevar a arrecadação da União, reverter o fluxo de transferências para as unidades subnacionais e enfrentar o problema fiscal. $\mathrm{O}$ argumento procede no sentido de o governo federal ter engendrado mudanças efetivamente substantivas, em cujo rol ainda se insere a instituição da Lei de Responsabilidade Fiscal (LC N. ${ }^{\circ}$ 101/2.000). O próprio sociólogo-presidente reflete sobre a experiência de seu governo à luz do debate sobre a reforma do Estado:

Em primeiro lugar, no mundo atual (se não quisermos o Estado mínimo), é preciso que os governos não apenas sejam representativos (e, portanto, correspondam, por meio do voto, à vontade do povo), mas que tenham capacidade de decidir. Para tal, fazem-se necessárias reformas que dêem higidez fiscal ao Estado e governabilidade. A questão da higidez fiscal, no nosso caso,

30 Oliveira, 1995: 144. 
passava, como passa, pela manutenção da estabilidade econômica, pelo equilíbrio orçamentário e pela criação de mecanismos que tornassem transparentes as contas do Estado... ${ }^{31}$

Abstraindo o conteúdo, digamos, mais ideológico da polêmica sobre o lugar e o tamanho do Estado, o peso atribuído às reformas nas dimensões fiscal e tributária assume caráter estratégico não só do ponto de vista da necessidade conjuntural de fazer caixa, mas sobretudo no sentido de orientar e (re)capacitar o Estado a assegurar universalização do acesso a bens e serviços Apesar das aparências ou mesmo do esforço governamental, a recorrência desses mesmos temas - disputas freqüentes em torno do pacto federativo, agonia financeira dos governos e forte pressão das dívidas, que reduzem drasticamente a capacidade de investimento - são suficientes para demonstrar que o problema ainda está longe de ter sido solucionado.

Particularmente para os municípios, este padrão pendular de movimentos ora descentralizantes ora reconcentradores não superou a forte dependência das transferências, em que pese o mencionado $e$ significativo crescimento das receitas próprias verificado ao longo década de 1990. Apesar do movimento mais recente em sentido oposto e das generosas potencialidades ainda inexploradas, a baixa capacidade de o Poder Local gerar receitas próprias segue distinguindo o federalismo brasileiro. A tal componente deve-se agregar a limitação de sua alçada decisória no que concerne ao estabelecimento de políticas macroeconômicas - prerrogativa exclusiva do governo federal e de suas correspondentes agências e instituições. De resto, não se deve ignorar a própria historicidade política do recente processo de descentralização no Brasil, cuja tônica envolveu não apenas o sincero desejo de desconcentrar recursos de poder, mas também interesses conflitantes resultantes das seculares clivagens regionais. De outra parte, é impossível falar de descentralização sem que ocorra um movimento razoavelmente simétrico de distribuição de recursos e de encargos.

Independente dessas variáveis e das derrotas que se seguiram à vitória de 1988, os municípios vêm desempenhando um papel cada vez mais importante no desenho político nacional, tanto porque o exercício da fiscalização da sociedade é favorecido, quanto porque a complexidade da problemática urbana permanece desafiando os gestores pú-

31 Cardoso, 1998: 8-9. 
blicos a oferecer respostas responsivas a temas vitais como participação e políticas sociais. Dessa perspectiva, a Constituição de 1988 constitui um marco altamente positivo, pois, além de elevar as receitas municipais, afirmou o município como ente federativo dotado de personalidade jurídica $e$ lhe atribuiu grandes responsabilidades na gestão urbana. Esta atribuição relacionada ao estabelecimento de diretrizes de política urbana foi acentuada com a promulgação da Lei n. $^{\circ}$ 10.257, de 10 de julho de 2001, que regulamenta os Artigos n. ${ }^{\circ} 182$ e n. ${ }^{\circ} 183$ da Constituição, consubstanciada no assim conhecido "Estatuto da Cidade" - instrumento que amplia sensivelmente a capacidade de intervenção do Poder Local sobre seu próprio território. Abstraindo, portanto, a síntese tributária, é consagrada a percepção de que as cidades constituem locus privilegiados do sistema governativo.

À medida que as demandas locais incidem direta e proximamente sobre os governos municipais, a capacidade de pressão social, o poder de controle e fiscalização e a accountability tendem a ser significativamente maiores. Aumentando-se a porosidade do Estado e dotando suas relações com a sociedade civil de mais proximidade, o controle sobre as ações governativas pode ser exercido de forma mais eficaz porque diz respeito a assuntos diretos e tangíveis. Obviamente, tratamse de tendências e possibilidades, que serão tanto mais verossímeis quanto mais republicanos, responsivos e democráticos forem os compromissos e os programas dos governos, e mais sólida a capacidade organizativa da sociedade civil.

O aumento das prerrogativas dos municípios, no sentido de gozarem de maior autonomia política, administrativa e financeira, e a conseqüente emergência do Poder Local como foco de reorganização social inauguram um novo período na política nacional, no qual a reforma do Estado é processada mediante uma tendência descentralizante que desconcentra poderes e que, de forma subjacente, abre novas possibilidades de articulação e controle da sociedade civil. O próprio advento do Orçamento Participativo constitui uma demonstração desta tendência à maior participação cidadã (Goulart, 2002). Tais componentes trazem consigo uma carga de renovação política que contrasta fortemente com a tradição autoritária, patrimonialista e centralista que caracterizaram a dominação política e o sistema governativo no Brasil durante largo período. Não é tudo, mas não é pouco. 


\section{Referências bibliográficas}

ABRUCIO, Fernando. Os barões da federação: os governadores e a redemocratização brasileira. São Paulo: Hucitec-DCP/USP, 1998.

Afonso, José R. R.; Araujo, Erika A. A capacidade de gastos dos municípios brasileiros: arrecadação própria e receita disponível. Cadernos Adenauer 4: Os municípios e as eleições de 2000. São Paulo: Fundação Konrad Adenauer, jun. 2000.

AfFonso, Rui de B. A. Descentralização e reforma do Estado: a Federação brasileira na encruzilhada. Economia e Sociedade, n. 14. Campinas: Instituto de Economia/Unicamp, 2000.

Almeida, Maria Hermínia T. Federalismo e políticas sociais. Revista Brasileira de Ciências Sociais, n. 28. São Paulo: ANPOCS, 1995.

CARDoso, Fernando H. Notas sobre a reforma do Estado. Novos Estudos, n. 50. São Paulo: CEBRAP, 1998.

DiAS, Guilherme L. S. Reformas econômicas: o eixo federativo e as novas coalizões. In: Sola, Lourdes; Paulanı, Leda M. (Orgs.). Lições da Década de 80. São Paulo: EDUSP, 1995.

Dowbor, Ladislau. Governabilidade e descentralização. 1994. Mimeografado.

EscobAr, Santiago; Solari, Ricardo. El municipio y la democracia moderna. Nueva Sociedad, n. 142. Caracas, 1996.

FIGUEIREDO, Argelina et al. Governabilidade e concentração de poder institucional o governo FHC. Tempo Social, v. 11, n. 2. São Paulo: DS-FFLCH/USP, 2000.

Goulart, Jefferson O. Esquerda e poder: a gestão petista na Prefeitura de Piracicaba (1989-1992). São Paulo, 1996. Dissertação (Mestrado em Ciência Política) - Faculdade de Filosofia, Letras e Ciências Humanas, Universidade de São Paulo.

. Poder Local e novas experiências democráticas. São Paulo, 2002. Tese (Doutorado em Ciência Política) - Faculdade de Filosofia, Letras e Ciências Humanas, Universidade de São Paulo.

Kugelmas, Eduardo; SolA, Lourdes. Recentralização/Descentralização - dinâmica do regime federativo no Brasil dos anos 90. Tempo Social, v. 11, n. 2. São Paulo: DS-FFLCH/USP, 2000.

Leme, Heládio J. C. O Federalismo na Constituição de 1988: representação política e a distribuição de recursos tributários. Campinas, 1992. Dissertação (Mestrado) - Instituto de Filosofia e Ciências Humanas, Unicamp.

Maffezol, Lineu C. Políticas sociais descentralizadas: análise da municipalização dos serviços de saúde em Piracicaba. In: Terci, Eliana T. (Org.). O desenvolvimento de Piracicaba: história e perspectivas. Piracicaba: Editora Unimep, 2001. 
MENDOZA, Enrique C. Las políticas descentralizadoras en el ámbito internacional - retos y experiencias. Nueva Sociedad, Caracas, n. 142, 1996.

Oliveira, Fabrício A. Crise, reforma e desordem do sistema tributário nacional. Campinas: Ed. Unicamp, 1995.

SAllum JR., Brasílio. Federação, autoritarismo e democratização. Tempo Social. São Paulo: DS-FFLCH/USP, v. 8, n. 2, 1996.

O Brasil sob Cardoso - neoliberalismo e desenvolvimentismo. Tempo Social. São Paulo: DS/FFLCH/USP, v. 11, n. 2, 2000.

SolA, Lourdes. Estado, regime fiscal e ordem monetária: qual Estado? In: Sola, Lourdes; Paulani, Leda M. (Orgs.). Lições da Década de 80. São Paulo: EDUSP, 1995.

SouzA, Israel V.; PIRES, Valdemir A. O impacto das mudanças tributárias da Constituição de 1988 sobre a receita transferida - Piracicaba: 1988-1993. In: TERCI, Eliana T. (Org.). O desenvolvimento de Piracicaba: história e perspectivas. Piracicaba: Editora Unimep, 2001.

VAESANO, Ricardo et al. Uma análise da carga tributária no Brasil. Texto para discussão, n. 583. Rio de Janeiro: IPEA, 1998. 